\title{
Quality of care in the delivery room: Focusing on respectful maternal care practices
}

\author{
Ola Mousa*1, Oscar M. Turingan² \\ ${ }^{1}$ College of Nursing, Minia University, Minya, Egypt \\ ${ }^{2}$ University of Nizwa, Nizwa, Ad Dakhiliyah, Oman
}

Received: June 14, 2018

DOI: $10.5430 /$ jnep.v9n1p1
Accepted: August 12, 2018

Online Published: August 22, 2018

URL: https://doi.org/10.5430/jnep.v9n1p1

\begin{abstract}
This study provided a descriptive overview of the care provided in the delivery room focused on respectful maternity care as perceived by women during labor and delivery in a maternity and child health hospital in Egypt. The dimensions examined were those related to services that arepatient-friendly, free of abuse, timely and free of discrimination. A cross-sectional retrospective study was conducted at the postpartum department in Minia University Maternity and Child Health Hospital in Minia, Egypt. Purposive sampling technique was used to recruit participants from a population of postpartum women who delivered their babies in the hospital, received delivery services from 6 hours to 7 days before the study period. The 15-item Respectful Maternal Care (RMC) Scale was used for this study. A total of 580 questionnaires were distributed to the postpartum women in the hospital and 501 were completed and collected giving a retrieval rate of $86.4 \%$. The findings indicated that majority of the postpartum mothers felt that they received friendly care, abuse-free care and a timely care on a moderate degree during childbirth. Generally, the postpartum mothers felt that they received a high degree of discrimination free care during childbirth. Overall, the postpartum mothers in this study experienced moderate degree of respectful maternity care during childbirth. Although the general findings show moderate respectful maternity care, more than fifty percent of the postpartum mothers experienced being shouted at by healthcare workers and more than half of the postpartum mothers claim that they were not given prompt service by the healthcare workers and waiting time is long. These aspects of maternity care need to be improved.
\end{abstract}

Key Words: Respectful care, Labor and delivery, Maternity care, Egypt

\section{INTRODUCTION}

\subsection{Introduction to the problem}

Every childbearing woman receiving healthcare services in any setting deserves respectful care by maternity care providers. The lack of respect and the experience of being abused during the process of labor and delivery discourages many women from obtaining professional maternity care. This may result in increased cases of birth injury and even maternal and newborn deaths. In spite of severe impacts, such disrespect and abuse during childbirth remain concealed and are rarely disclosed especially in developing countries. ${ }^{[1]}$
Respectful maternity care (RMC) concept acknowledges the meaningful experiences of childbirth by women as an essential elementof quality health care, which involves recognizing their self-worth, feelings, choices, and preferences. It is globally recognized as a universal human right for every childbearing woman admitted in any health facility. ${ }^{[2]}$ There is, however, lack of a common understanding on how the concept of respectful maternity care is defined although it is used similarly with the terms women-friendly care and women-centered care. ${ }^{[3]}$

Efforts to recognize and deal with mistreatment of child-

*Correspondence: Ola Mousa; Email: olaessam1977@yahoo.com; Address: College of Nursing, Minia University, Minya, Egypt. 
bearing women admitted at maternal health facilities have increased internationally. Eliminating practices of disrespect or abuse and changing it with respectful maternity care practices is clearly one of the most important interventions that is worth fulfilling. This has also been the focus of interest in some studies. As a starting point for research and action, Freedman et al. defined disrespect and abuse in childbirth as exchanges orsituations that local agreement believes to be disgracing or unbecoming and those that are experienced as or intended to be "humiliating or undignified". The authors expect this definition to be in agreement with both national and human rights guidelines for respectful maternity care. ${ }^{[4]}$

Bowser and Hill explored proof for disrespect and abuse in facility-based childbirth and presented available facts and evidence on this issue. From a complete review of the proof or indicators, their study identified seven types of lack of respect and mistreatment that happen in labor and delivery namely: physical mistreatment, care without consent, untrustworthy care, undignified care, intolerance on specific patient characteristics, neglect of care, and confinement in facilities. ${ }^{[5]}$ Rosen et al. observed in their study the presence of physical and verbal abuse of women and the most common form of disrespect and abuse was abandonment and neglect. The authors contended that more studies are needed to comprehend and come up with useful interventions to advocate respectful care in health facility situation. ${ }^{[6]}$

A survey of key countries about their experiences implementing interventions to prevent disrespect and abuse during childbirth was conducted by Reis, Deller, Carr and Smith. ${ }^{[7]}$ Their efforts supported the promotion of respectful maternity care, which recognizes that safe motherhood, should develop outside prevention ofinjury or death to include respect for women's basic human rights. In addition, indicators on the frequency and occurrence of respectful care practices at a health-care facility in low-level settings are still limited. ${ }^{[5,8]}$ Regardless of the challenge and the difficulty of this subject, Reis et al.found that nowadays concern is developed in promoting respectful maternity care in many countries. ${ }^{[7]}$

Sheferaw, Mengesh and Wase found that lack of respect and mistreatment during childbirth are essential obstacles for service utilization at healthcare facilities. With this situation, the authors promoted theimportance of havinga reliable and valid tool to determine women's views and insights on respectful maternity care that will encourage utilization of maternity care services. Hence, the authors developed the RMC tool that will also help managers of healthcare facilities to examine the level of satisfaction of patients with the services. ${ }^{[3]}$

Indeed, there is a rising interest about the quality of care that women are experiencing during labor and delivery. Interest in promoting respectful maternity care in many countries, including interventions to address the issue of disrespect and abuse during maternity care has become the focus of concern among maternal health interest groups. ${ }^{[7]}$

Despite the agreed interest of achieving respectful, nonabusive maternity care for all women, there has been paucity of research around this topic. The purpose of this study is to provide a descriptive overview of the quality of care in the delivery room focused on respectful maternity care as perceived by women during labor and delivery in a maternity and child health hospital in Minia, Egypt.

\section{METHOD}

This was a cross-sectional retrospective study conducted at the postpartum department in Minia university maternity and child health hospital in Egypt from May 1 to October 31, 2017. Purposive sampling technique was used to recruit participants from a population of postpartum women who delivered their babies in the hospital, received delivery services from 6 hours to 7 days before the study period, could speak Arabic and gave written consent to participate in this study. A total of 580 questionnaires were distributed to the postpartum women in the hospital and 501 were completed and collected giving a retrieval rate of $86.4 \%$. The 15 -item RMC Scale ${ }^{[3]}$ was used for this study with slight rewording. To use the scale for the purpose of this study, a written approval was taken from the authors. The scale has four dimensions related to services that are patient-friendly, free of abuse, timely and free of discrimination. After receiving the information about the study purpose and objectives, the respondents were asked to provide their opinion for each question on a scale of $1=$ strongly disagree to $5=$ strongly agree. The RMC scale in English was translated into Arabic and pretested on 30 participants to improve content validity and were excluded from the sample.

To protect the rights of the participants, a written informed consent was taken from them. Ethical approval was taken from the Research Ethics Committee of the Maternal and Child Health Hospital.All data collected were aggregated and statistically calculated using the Statistical Package for the Social Sciences (SPSS 16.0). Frequency and percentage (\%) distribution were used to present the demographic profile and the responses of participants to the questionnaire items. Weighted mean (M) was used to describe the level of respectful maternity care experienced by the postpartum women during childbirth. To determine the participants' degree of respectful maternal care, the following Likert-range conversion and qualitative interpretation was used: $4.20-5.00$ is Very High, 3.40-4.19 is High, 2.60-3.3 is Moderate, 1.80-2.5 
is Low, and 1-1.79 is Very Low.

\section{RESULTS AND DISCUSSION}

\subsection{Demographic profile of postpartum women}

Table 1 shows the demographic profile of the postpartum women. Nearly half $(43 \%)$ of the postpartum women in the study have an age ranging from 30 to 40 years. Considering their educational status, about $41 \%$ have bachelor's degree, $23 \%$ finished primary school, $20 \%$ finished secondary level, and $11 \%$ are illiterate. In terms of socio-economic status about $59.8 \%$ of the postpartum women belong to middle class family; the remaining $20 \%$ come from the upper class while $20.2 \%$ belong to lower class. Occupational status of the postpartum women revealed that majority $(62.8 \%)$ are house wives and the remaining $37.2 \%$ are working mothers. Regarding the number of children, about $60 \%$ of the postpartum women mentioned that they have more than one child, while the remaining $40 \%$ had one child only.

Table 1. Frequency and percentage distribution of demographic profile of the postpartum women

\begin{tabular}{lll}
\hline Demographic Characteristics & Frequency & \% \\
\hline Age & 56 & 11 \\
$<20$ & 165 & 33 \\
$20-30$ & 215 & 43 \\
$30-40$ & 65 & 13 \\
$>40$ & & \\
Educational Status & 56 & 11 \\
$\quad$ Illiterate or read and write & 115 & 23 \\
$\quad$ Primary education & 100 & 20 \\
$\quad$ Secondary education & 205 & 41 \\
$\quad$ Bachelor's degree & 25 & 4 \\
$\quad$ Master's degree/Doctorate degree & & \\
Socio Economical Status & 100 & 20 \\
$\quad$ Upper Class & 300 & 59.8 \\
$\quad$ Middle Class & 101 & 20.2 \\
$\quad$ Lower Class & & \\
Occupational Status & 186 & 37.2 \\
$\quad$ Working Women & 315 & 62.8 \\
$\quad$ House Wife & & \\
Obstetrical History & 200 & 40 \\
$\quad$ Number of children (1) & 301 & 60 \\
More than one child & & \\
\hline
\end{tabular}

\subsection{Respectful maternity care as perceived by women during labor and delivery}

Based on the mean score of the 15 items on the questionnaire, the postpartum mothers in this study experienced moderate degree of respectful maternity care during childbirth $(\mathrm{M}=$ 3.23). The postpartum mothers' right to receive a respectful maternity care is divided into four dimensions. The following are the descriptive statistics for the four dimensions of respectful maternity care as perceived by the postpartum mothers.

\subsubsection{Friendly care}

Table 2 shows that a majority of the postpartum mothers felt that they received friendly care on a moderate degree during childbirth (Mean $=3.18)$. Specifically, a majority of the postpartum mothers felt that healthcare workers approached them in a kind manner (74.45\%), healthcare workers were friendly in their treatment $(73.05 \%)$, sounded positively on topics about pain and its relief (59.9\%) and addressed them by their names $(50.9 \%)$. Less than fifty percent of the postpartum mothers however, felt that the health workers were concerned and empathic and treated them with respect as individuals. It is interesting to note that majority of the postpartum mothers disagree that healthcare workers communicated to them in a language within their level of understanding (61.48\%).

The findings of this study showed a more positive experience of postpartum mothers on receiving friendly care from healthcare providers as compared to the experiences of postpartum mothers reported in the literature. According to WindauMelmer, service providers must ensure that patients are as comfortable as possible and that every woman seeking care is a person of value and has the right to be treated with respect and consideration. ${ }^{[2]}$ Bohren et al. reports that unfriendly care of women by health providers during childbirth was a commonly reported event, particularly the use of harsh or rude language. ${ }^{[8]}$

\subsubsection{Abuse free care}

Generally, the postpartum mothers felt that they received a moderate degree of abuse free care during childbirth (Mean $=3.23$ ) as shown in Table 2. Specifically, a majority of postpartum mothers felt that health workers responded to their needs in an appropriate manner (61.68\%). Majority disagree that health workers hit them during delivery for different reasons (83.03\%). However, more than fifty percent of the postpartum mothers experienced being yelled at by healthcare workers because they have not done what they were told to do during childbirth.

It is interesting to note that in this study, postpartum mothers experienced positive treatment during childbirthand did not experience physical abuse although verbal abuse has been reported. In the study of Windau-Melmer, many stories of physical abuse during childbirth have been reported. ${ }^{[2]} \mathrm{Re}-$ sult of this study is similar with reports of Rosen et al. where women overall were treated with dignity and in a supportive manner by providers, but many women experienced poor interactions with providers and verbal abuse of women were observed. ${ }^{[6]}$ 
Table 2. Frequency and percent distribution and mean scores for the different dimensions of respectful maternity care $(\mathrm{N}=$ 501)

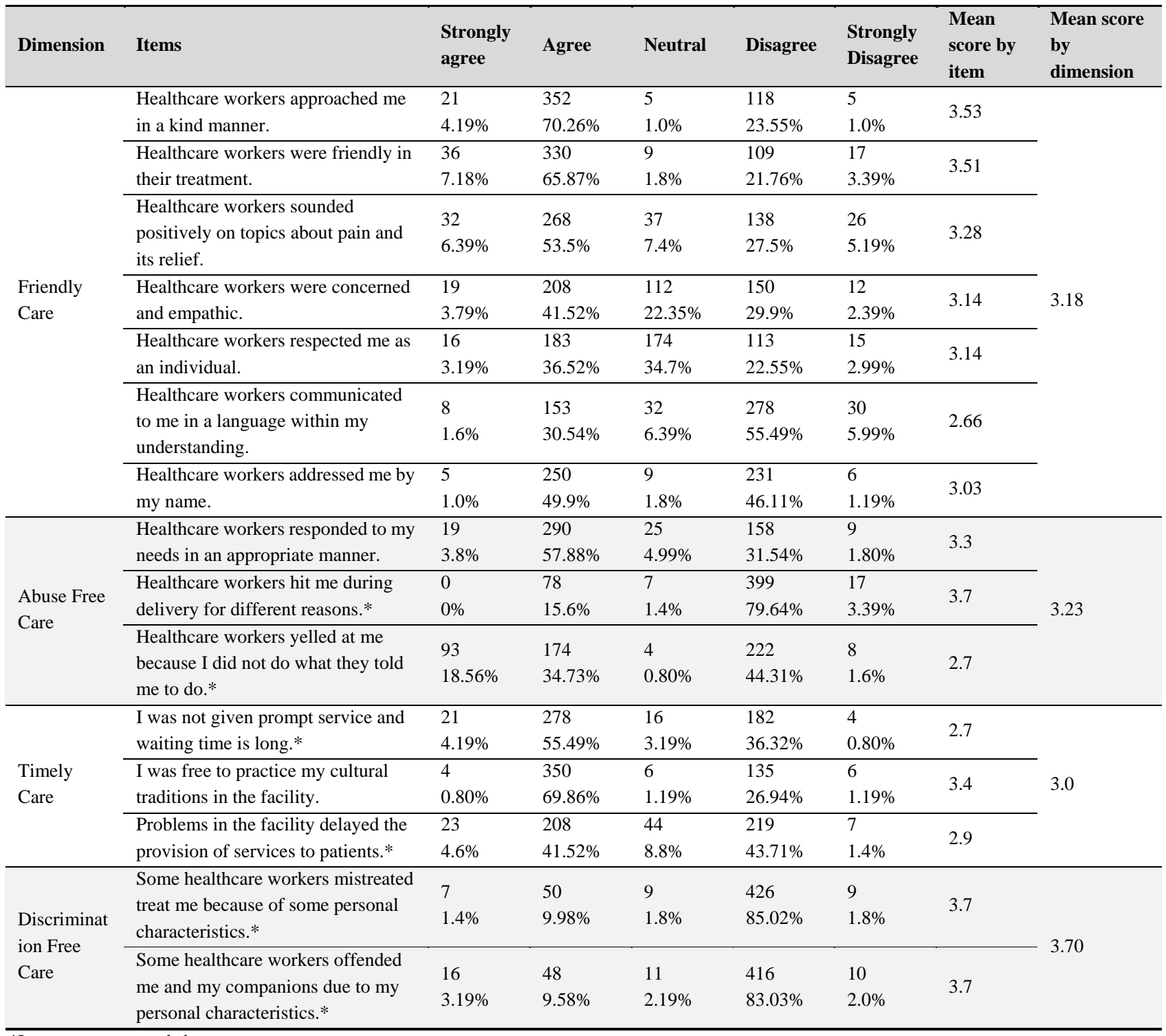

*Items are reverse coded.

\subsubsection{Timely care}

The postpartum mothers' responses to timely maternity care are shown in Table 2. The results indicated that generally, the postpartum mothers felt that they received a timely care on a moderate degree during childbirth (Mean $=3.0$ ). Most of the postpartum mothers claimed that they were allowed by the healthcare workers to practice cultural traditions in the facility $(70.66 \%)$. More than half of the postpartum mothers however, stated that they were not given prompt service and waiting time is long (59.68\%). In terms of delay in service provision due to the health facilities' internal problem, $46.12 \%$ of the postpartum mothers agree, while $45.11 \%$ disagree. These findings are supported by Rosen et al. noting delays in care and abandonment of women dur- ing labor, delivery, and postpartum were the most frequent type of respectful maternity care rights violation. ${ }^{[6]}$ Bohren et al. also reported that women frequently referred to long delays in receiving care and inattentive health workers who neglected women during labor and delivery. ${ }^{[8]}$

\subsubsection{Discrimination free care}

The results of responses on discrimination free care by postpartum mothers in this study are shown in Table 2. In general, the postpartum mothers felt that they received a high degree of discrimination free care during childbirth (Mean $=3.75$ ). Majority of the postpartum mothers felt that healthcare workers mistreated them because of some personal characteristics $(86.82 \%)$. On the other hand, the postpartum mothers dis- 
agree on the statement that health workers offended them and their companions because of their personal characteristics $(85.03 \%)$.

These findings are contrary to what has been reported in the literature where patients felt discriminated during labor and delivery. Bohren et al. reported that women commonly reported feeling discriminated due to their ethnic or racial backgrounds. ${ }^{[8]}$ Windau-Melmer however, contends that all women are equal and must be treated with respectful care regardless of their ethnic background, culture, social standing, educational level, or economic status. ${ }^{[2]}$ According to the WHO meeting in Mexico,women-friendly services have to provide high technical quality, accessible, reasonable and culturally acceptable care, which could empower and satisfy users, as well as support and motivate providers. ${ }^{[9]}$ In another study who delivered in Nigeria women are suffering from indorsing physical abuse and verbal abuse. ${ }^{[10]}$

\section{Conclusion}

This study provided a descriptive overview of the care provided in the delivery room focused on respectful maternity care as perceived by women during labor and delivery in a maternity and child health hospital in Egypt. The dimensions examined were those related to services that are patientfriendly, free of abuse, timely and free of discrimination. Majority of the postpartum mothers felt that they received friendly care, abuse-free care and a timely care on a moderate degree during childbirth. Generally, the postpartum mothers felt that they received a high degree of discrimination free care during childbirth. Overall, the postpartum mothers in this study experienced moderate degree of respectful maternity care during childbirth. Although the general findings show moderate respectful maternity care, more than fifty percent of the postpartum mothers experienced being shouted at by healthcare workers because they have not done what they were told to do during childbirth. Moreover, more than half of the postpartum mothers claim that they were not given prompt service and waiting time is long. These aspects of maternity care need to be improved. Every healthcare provider must be aware that respectful maternity care (RMC) is a universal human right that is due to every childbearing woman. ${ }^{[2]}$ Persuading healthcare leaders and service providers and keeping them accountable can help improve respectful maternity care and meet patients' needs.

\section{CONFlicts of InTERest Disclosure}

The authors declare that there is no conflict of interest.

\section{REFERENCES}

[1] Azhar Z, Oyebode O, Masud H. Disrespect and abuse during childbirth in district Gujrat, Pakistan: A quest for respectful maternity care. Annals of Global Health. 2017; 83(1): 94-109.

[2] Windau-Melmer T. A guide for advocating for respectful maternity care. Washington, DC: Futures Group, Health Policy Project; 2013.

[3] Sheferaw ED, Mengesha TZ, Wase SB. Development of a tool to measure Women's perception of respectful maternity care in public health facilities. BMC Pregnancy and Childbirth. 2016; 16(67): 1-8.

[4] Freedman, et al. Defining disrespect and abuse of women in childbirth: a research, policy And rights agenda. Bulletin of the World Health Organization. 2014; 92: 915-917. PMid:25552776 https : //doi.org/10.2471/BLT.14.137869

[5] Bowser D, Hill K. Exploring Evidence for Disrespect and Abuse in Facility-based Childbirth: Report of a Landscape Analysis. Bethesda, MD: USAID-traction Project, Harvard School of Public Health. 2010.
[6] Rosen HE, Lynam PF, Carr C, et al. Direct Observation of respectful maternity care in five countries: a cross-sectional study of health facilities in East and Southern Africa. BMC Pregnancy and Childbirth. 2015; 15: 306. PMid:26596353 https://doi.org/10.1186/s1 2884-015-0728-4

[7] Reis V, Deller B, Carr C, et al. Respectful maternity care country experiences. Maternal and Child Health Integrated Program Survey Report. 2012. Available from: https://www.k4health.org/sit es/default/files/RMC\%20Survey\%20Report_0.pdf

[8] Bohren MA, Vogel JP, Hunter EC, et al. The Mistreatment of women during childbirth in health facilities globally: A mixed-methods systematic review. Plosmed. 2015; 12(6): e1001847.

[9] World Health Organization (WHO), UNICEF, UNFPA. Womenfriendly health services: Experiences in maternal care. Mexico City: WHO/UNICEF/UNFPA. 1999.

[10] Bohren MA, Vogel JP, Tunçalp Ö, et al. Mistreatment of women during childbirth in Abuja, Nigeria: a qualitative study on perceptions and experiences of women and healthcare providers. Pubmed. 2017. 